\title{
Crowning of dibenzosilole with a naphthalenediimide functional group to prepare an electron acceptor for organic solar cells
}

Akhil Gupta $^{\mathrm{a}, 1, *}$, Rahul V. Hangarge ${ }^{\mathrm{b}, 1}$, Xizu Wang ${ }^{\mathrm{c}, 1}$, Ben Alford ${ }^{\mathrm{a}}$, Vijila Chellapan ${ }^{\mathrm{c}}$, Lathe A. Jones ${ }^{\mathrm{a}, \mathrm{d}}$, Anushri Rananaware $^{\mathrm{a}}$, Ante Bilic ${ }^{\mathrm{e}}$, Prashant Sonar, f,, , Sheshanath V. Bhosale, ${ }^{\mathrm{a}, *}$

${ }^{a}$ School of Applied Sciences, RMIT University, GPO Box 2476, Melbourne Victoria 3001 Australia; Tel: +613 9925 2680; E-mail: sheshanath.bhosale@rmit.edu.au; akhilgk15@gmail.com

${ }^{b}$ Department of Organic Chemistry, School of Chemical Sciences, North Maharashtra University, Jalgaon 425 001 Maharashtra, India

${ }^{c}$ Institute of Materials Research and Engineering (IMRE), 3, Research Link, Singapore 117602

${ }^{d}$ Centre for Advanced Materials and Industrial Chemistry (CAMIC), RMIT University, GPO Box 2476, Melbourne Victoria 3001 Australia

${ }^{e}$ CSIRO Manufacturing, Virtual Nanoscience Lab, Parkville Victoria 3052 Australia

${ }^{f}$ School of Chemistry, Physics and Mechanical Engineering, Queensland University of Technology, GPO Box 2434, Brisbane QLD 4001 Australia; E-mail: sonar.prashant@qut.edu.au

${ }^{1}$ These authors contributed equally to this work

\section{Abstract}

A novel, solution-processable non-fullerene electron acceptor 9,9'-(5,5-dioctyl-5Hdibenzo[b,d]silole-3,7-diyl)bis(2,7-dioctyl-4-(octylamino)benzo[lmn $][3,8]$ phenanthroline1,3,6,8(2H,7H)-tetraone) (B3) based on dibenzosilole and naphthalenediimide building blocks was designed, synthesized, characterized and successfully used in a bulkheterojunction organic solar cells. B3 displayed excellent solubility, thermal stability and acquired electron energy levels matching with those of archetypal donor polymer poly(3hexylthiophene). Solution-processable bulk-heterojunction devices afforded $1.16 \%$ power conversion efficiency with a high fill factor of 53\%. B3 is the first example in the literature using this design principle, where mild donor units at the peripheries of end-capped 
naphthalenediimide units tune solubility and optical energy levels simultaneously.

\section{Introduction}

Over the last decade, the development of solution-processable bulk-heterojunction (BHJ) solar cells has seen a dramatic surge due to intense research activity, resulting in increased power conversion efficiencies (PCEs) [1-5]. For most research groups, increasing the PCE has been a key aim and PCEs have increased from less than $1 \%$ in the initial reports to $10 \%$ in recent publications [6]. However, increasing efficiencies usually stem from the development of new electron donor materials that exhibit improved optoelectronic properties, such as light harvesting, and favourably tuned highest occupied molecular orbital (HOMO) and lowest unoccupied molecular orbital (LUMO) energy levels, which match with those of electron acceptors [1]. In fact, electron acceptors are materials which should be considered as equally important as donor materials. But in practice, the development of electron acceptors has trailed far behind that of donors. It is thus desirable that further research is carried out on the development of electron acceptor materials.

With regards to electron acceptor materials, conventional fullerenes and their derivatives, such as $[6,6]$-phenyl- $\mathrm{C}_{61}$-butyric acid methyl ester $\left(\mathrm{PC}_{61} \mathrm{BM}\right)$ and its $\mathrm{C}_{71}$ analogue $\mathrm{PC}_{71} \mathrm{BM}$, are the most common acceptors of choice, thanks to their superior electron affinity and good electron mobility [7-8]. Despite these inherent properties, fullerene derivatives are afflicted with a number of disadvantages, such as weak absorption in the visible spectrum, restricted electronic tuning, and a large electron affinity that can result in low open-circuit voltages $\left(V_{\text {oc }}\right.$ [9]. Hence, incentives remain to develop non-fullerene electron acceptors that retain the favourable properties of fullerene derivatives and also overcome their insufficiencies. In order to design new acceptors, one has to consider desirable properties such as (1) strong and broad absorption, (2) high charge carrier mobility, (3) solubility and (4) appropriate energy levels. Currently, a popular strategy for tailoring the properties of electron acceptors is 
through assimilating electron-withdrawing building blocks which are illustrated by, but not limited to, cyano, carbonyl, amide, imide groups and their emerging analogues. Therefore, it is not surprising that there exists a growing interest for the development of small molecular non-fullerene acceptors for solution-processable BHJ devices. Key examples of this approach were recently reported by P. Sonar et al. and Y. Lin et al. [10-11].

Recently, inspired by the brisk development of electron- and hole-transporting materials for organic electronics, various research groups have begun to explore non-fullerene acceptors for solution-processable BHJ devices [12-21]. PCEs linger around $2 \%$ and $4 \%$ with the use of classical donor polymer poly(3-hexylthiophene) (P3HT) and non-P3HT donors, respectively [22-29]. This progress is promising, albeit appreciable scope still exists to develop new non-fullerene acceptors which possess strong optical absorption, good photochemical stability and adequate solubility. In line with this outlook, functionalities such as dibenzosilole (DBS) and naphthalenediimide (NDI) have shown considerable promise as versatile building blocks for the development of non-fullerene acceptors. We and others have successfully shown examples of target materials based on such building blocks [10, 23, 30]. In this study we have chosen the DBS and NDI functionalities to be used in conjunction to design and develop a target material that (1) possesses elongated conjugation with good structural planarity, (2) shows high chemical and thermal stability, and (3) is highly soluble in common organic solvents. Keeping in mind that solubility is a critical requirement, we further envisioned the incorporation of peripheral lipophilic chains on the terminal NDI functionalities. This was done in practice by choosing a chemical entity (-octylamine) that contains nitrogen, a conventional donor atom. The use of such donor atoms has been successful in fine tuning optical energy levels [31]. The inclusion of such extraneous chains is in addition to the conventional alkyl chains already present on the nitrogen and silicon atoms of NDI and DBS functionalities, respectively. Such a target material with eight alkyl 
chains (all the chains were selected to be identical (-octyl) from a molecular symmetry point of view) is a highly conjugated and well-proportioned molecule, and is highly novel on its own. The presence of these alkyl chains not only helps to enhance the solubility of target chromophore, but also demonstrates excellent film forming properties without crystallization occurring in the film. The presence of free hydrogen atoms on the terminal nitrogen atoms assists to enhance the intra- and intermolecular interactions for a better $\pi-\pi$ stacking. The target material reported herein, 9,9'-(5,5-dioctyl-5H-dibenzo[b,d]silole-3,7-diyl)bis(2,7dioctyl-4(octylamino)benzo[ $\operatorname{lmn}][3,8]$ phenanthroline-1,3,6,8(2H,7H)-tetraone), has been coded as B3 and carries a DBS functionality at the central core with NDI units carrying peripheral chains as terminal substituents end-capped at the both ends (see Fig. 1). An initial screen of efficacy of B3 as an $n$-type material was carried out by using it in a solutionprocessable BHJ device along with classical donor polymer P3HT. The BHJ device based on P3HT:B3 (1:1 w/w) exhibited PCE as high as $1.16 \%$ with a high fill factor (FF) of 53.4\%. This value of FF is amongst the top values for a small molecular non-fullerene acceptor which has been incorporated into a single-junction BHJ device without any special treatment. B3 is the first non-fullerene electron acceptor in the literature with DBS as a core and NDI as arms. The present work is a continuation of our efforts on the design and development of small molecular chromophores for organic electronic applications [32-35].

\section{FIGURE 1 GOES HERE}

\section{Experimental section}

\subsection{Materials and instruments}

All the reagents and chemicals used, unless otherwise specified, were purchased from SigmaAldrich Co. The solvents used for synthetic reactions were obtained from Merck Speciality 
Chemicals (Sydney, Australia) and were used as received. 4,9-dibromo-2,7dioctylbenzo[lmn $][3,8]$ phenanthroline-1,3,6,8(2H,7H)-tetraone was reported previously [31]. Unless otherwise specified, all ${ }^{1} \mathrm{H}$ and ${ }^{13} \mathrm{C}$ NMR spectra were recorded using a Bruker AV400 spectrometer at $400 \mathrm{MHz}$ and $100.6 \mathrm{MHz}$, respectively, or a Bruker AV200 spectrometer at $200 \mathrm{MHz}$ and $50 \mathrm{MHz}$, respectively. Chemical shifts $(\delta)$ are measured in parts per million (ppm). Thin Layer Chromatography (TLC) was performed using $0.25 \mathrm{~mm}$ thick plates precoated with Merck Kieselgel 60 F254 silica gel, and visualised using ultraviolet (UV) light (254 nm and $365 \mathrm{~nm}$ ). Melting points were measured using a Gallenkamp MPD350 digital melting point apparatus and are uncorrected. High resolution mass spectra experiments were carried out on MALDI-TOF mass spectrometer. All ultraviolet-visible (UV-Vis) absorption spectra were recorded on a Hewlett Packard HP 8453 Diode array UVVis spectrophotometer. Thin films were spin-coated from $o$-dichlorobenzene (o-DCB) at a spin speed of $2000 \mathrm{rpm}$ for 1 min onto cleaned glass slides. B3 was spin-coated from solutions at a concentration of $20 \mathrm{mg} / \mathrm{mL}$. P3HT:B3 blend solutions were prepared in the same manner as for devices, i.e. P3HT $(15 \mathrm{mg})$ and B3 $(15 \mathrm{mg})$ in a total volume of $1 \mathrm{~mL}$. Where specified, films were annealed at $110^{\circ} \mathrm{C}$ for $5 \mathrm{~min}$. Fluorescence spectra were recorded using a Perkin-Elmer LS50B fluorimeter. Photoelectron Spectroscopy in Air (PESA) measurements were recorded using a Riken Keiki AC-2 PESA spectrometer with a power setting of $5 \mathrm{nW}$ and a power number of 0.5. Samples for PESA were prepared on clean glass substrates. The thermal stability of $\mathbf{B} 3$ was investigated by thermogravimetric analysis (TGA) and differential scanning calorimetry (DSC). Cyclic-voltammetry was performed in freshly distilled dichloromethane (over calcium hydride), with a supporting electrolyte of 0.1 M tetrabutylammoniumhexafluorophosphate (TBAPF6, Electrochemical grade, Aldrich) which was twice recrystallized from ethanol before use. A Glassy carbon electrode was used as a working electrode (ALS, Japan), which was polished with $0.05 \mu \mathrm{m}$ alumina on a felt pad, 
washed with distilled water followed by ethanol and dried under a $\mathrm{N}_{2}$ stream before use. A platinum wire was used as a counter electrode and a silver wire was used as a pseudo reference electrode. Ferrocene was used as an internal reference, by doping all solutions with an approximately equimolar amount of ferrocene. Reported voltammograms were recorded with a scan rate of $50 \mathrm{mV} / \mathrm{sec}$. Redox potentials (E1/2 values) were taken as a half way point between forward and reverse peaks for each reversible redox process.

\subsection{Device fabrication and characterization of photovoltaic devices}

Indium tin oxide (ITO)-coated glass (10 Ohms/square) was cleaned by standing it in a stirred solution of $5 \%(v / v)$ Deconex 12PA detergent at $90{ }^{\circ} \mathrm{C}$ for $20 \mathrm{~min}$. The ITO-coated glass was then successively sonicated for $10 \mathrm{~min}$ each in distilled water, acetone, and then isopropanol. The substrates were then exposed to a UV-ozone clean at room temperature for $10 \mathrm{~min}$. UV/ozone cleaning of glass substrates was performed using a Novascan PDS-UVT UV/ozone cleaner with the platform set to maximum height. The intensity of the lamp was $>36 \mathrm{~mW} / \mathrm{cm}^{2}$ at a distance of $10 \mathrm{~cm}$. At ambient conditions, the ozone output of the UV

cleaner is greater than 50 ppm. Aqueous solutions of poly $(3,4-$ ethylenedioxythiophene):polystyrene sulfonate (PEDOT:PSS) (HC Starck, Baytron P AI 4083) were filtered (0.45 $\mu \mathrm{m}$ PVDF filter) and deposited onto glass substrates in air by spin coating (Laurell WS-400B-6NPP lite single wafer spin processor) at $4000 \mathrm{rpm}$ for $60 \mathrm{~s}$ to give a layer having a thickness of $35 \pm 5 \mathrm{~nm}$. The PEDOT:PSS layer was then annealed on a hotplate in a glove box at $120{ }^{\circ} \mathrm{C}$ for $10 \mathrm{~min}$. For OPV devices, the newly synthesized organic $n$-type material (B3) and P3HT (Nano-C) were separately dissolved in individual vials by magnetic stirring. Blend ratios and solution concentrations were varied to optimize device performance. The solutions were then combined, filtered ( $0.45 \mu \mathrm{m}$ PTFE filter), and 
deposited by spin coating (SCS G3P spin coater) onto the ITO-coated glass substrates inside a glove box (with $\mathrm{H}_{2} \mathrm{O}$ and $\mathrm{O}_{2}$ levels both $<1$ ppm). Film thicknesses were determined on identical samples using a Dektak 6M Profilometer. The coated substrates were then transferred (without exposure to air) to a vacuum evaporator inside an adjacent nitrogen-filled glove box. Samples were placed on a shadow mask in a tray. The area defined by the shadow mask gave device areas of exactly $0.09 \mathrm{~cm}^{2}$. Deposition rates and film thicknesses were monitored using a calibrated quartz thickness monitor inside the vacuum chamber. Layers of calcium (Ca) (Aldrich), from an open tungsten boat, and aluminium (Al) (3 pellets of 99.999\%, KJ Lesker), from an alumina-coated graphite boat, having thicknesses of $15 \mathrm{~nm}$ and $100 \mathrm{~nm}$, respectively, were evaporated onto the active layer by thermal evaporation at pressures less than $2 \times 10^{-6}$ mbar.

Current density-voltage $(\mathrm{J}-\mathrm{V})$ characteristics of organic BHJ devices were measured under AM1.5 G illumination at $100 \mathrm{~mW} / \mathrm{cm}^{2}$ (SAN-EI Electric XEC-301S solar simulator). The light intensity of the solar simulator was calibrated using a monosilicon detector (with KG-5 visible colour filter) to minimize the spectral mismatch. The incident photon-to-currentconversion efficiency (IPCE) data was collected using an Oriel $150 \mathrm{~W}$ xenon lamp coupled to a monochromator and an optical fibre. The output of the optical fibre was focused to give a beam that was contained within the area of the device. IPCE data was calibrated with a standard, unfiltered Si cell and the data was corrected to the output of the calibrated AM1.5 solar simulator response. AFM topographic maps were performed directly on the active layer of the P3HT:B3 blends using an Asylum Research MFP-3D-SA instrument. The AFM was run in intermittent contact mode (tapping mode) using MicroMasch NSC18 tips (typical resonant frequency $\sim 100 \mathrm{kHz}$, typical probe radius $\sim 10 \mathrm{~nm}$ and typical aspect ratio 3:1). 


\subsection{Device preparation for thin film transistors}

We used thin film transistor (TFT) substrates Gen. 5: "end-of-line test substrates for customized semiconductor" purchased from Fraunhofer IMPS. Gate dielectric layers were

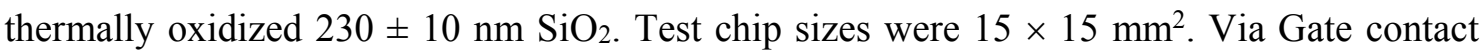
pads were $0.5 \times 0.5 \mathrm{~mm}^{2}$ structured by lift off technique. The $\mathrm{SiO}_{2}$ layer was cleaned with acetone followed by 2-propanol, and then treated with UV ozone. Bottom contact TFTs with pre-patterned source drain electrodes having a fixed channel width of $2000 \mu \mathrm{m}$ and varying channel lengths of $2.5,5,10,20 \mu \mathrm{m}$, with a total of 16 devices in one test chip were employed. Gate via, source drain contacts were $30 \mathrm{~nm}$ of Au with $10 \mathrm{~nm}$ high work function adhesion layer (ITO) (structured by lift off techniques). HMDS and OTS were applied as a passivation layer prior to the deposition of active layer. Device fabrication was completed by deposition of $\mathbf{B} 3$ (dissolved in $\mathrm{CHCl}_{3}$ ) by spin coating at $3000 \mathrm{rpm}$ for $1 \mathrm{~min}$. Measurements of the transistor characteristics were undertaken using an Agilent parameter analyser B1500A. Estimation of the carrier mobility was done using the standard transistor equation (1) in saturation mode:

$$
\mu=\frac{2 L}{W C_{i}}\left(\frac{\delta \sqrt{I_{D}}}{\delta V_{G}}\right)^{2}
$$

where $\mu$ is the two probe field effect mobility, $\mathrm{L}$ is the channel length, and $\mathrm{C}_{\mathrm{i}}$ is the gate insulator capacitance.

\subsection{Time of Flight Photoconductivity measurement}

The time of flight (TOF) photoconductivity system consists of a pulsed Nd:YAG laser pumped OPO (EKSPLA laser, pulse width $<5 \mathrm{~ns}, 1 \mathrm{~Hz}$ repetition rate), pulsed generator (SRS-DG535), a DC voltage source, and a digital oscilloscope (Agilant-Infiniium, $1 \mathrm{GHz}, 4$ 
Gsa/s). The sample for the measurement was prepared in simple device architecture of ITO/active layer $(1200 \mathrm{~nm}) / \mathrm{Al}$. The laser of wavelength $530 \mathrm{~nm}$ was used to excite the sample through the ITO side of the device. The photocurrent under the influence of applied electric field was monitored across a resistor $(\mathrm{R}=2 \mathrm{k} \Omega)$ using an oscilloscope. Care has been taken in order to ensure that the measurement is carried out in integrated mode TOFphotoconductivity where the time taken to collect the maximum charge corresponds to the carrier transit time $\left(\mathrm{t}_{\mathrm{m}}\right)$. The TOF transients were measured by applying different negative voltages to the ITO electrode in order to measure the electron mobility. The time taken to collect maximum charges $\left(t_{m}\right)$ corresponds to the transit time. The charge mobility $\mu$ was calculated using the relation of $\mu=\mathrm{d}^{2} / \mathrm{t}_{\mathrm{m}} \mathrm{V}$, where $\mathrm{d}$ is the film thickness and $\mathrm{V}$ is the applied voltage.

\section{$2.5 \quad$ Synthesis of $\mathbf{B} 3$}

Compound B3 was successfully synthesized via the Suzuki coupling reaction between the commercially available bis-boronic ester derivative of DBS, 5,5-dioctyl-3,7-bis(4,4,5,5tetramethyl-1,3,2-dioxaborolan-2-yl)-5H-dibenzo[ $[b, d]$ silole, and the penultimate monobromo derivative, 4-bromo-2,7-dioctyl-9-(octylamino)benzo[lmn][3,8]phenanthroline1,3,6,8(2H,7H)-tetraone (1), using tetrakis(triphenylphosphine)palladium(0) $\left[\mathrm{Pd}\left(\mathrm{PPh}_{3}\right)_{4}\right]$ as the catalyst (See Scheme 1). The reaction was carried out in dimethoxyethane at $120^{\circ} \mathrm{C}$ for 24 h using cesium carbonate as a base. B3 was purified by simple column chromatography and was fully characterized by high resolution mass spectrometry (HRMS), ${ }^{1} \mathrm{H}$ NMR and ${ }^{13} \mathrm{C}$ NMR spectroscopic techniques.

\section{Scheme 1 GOES HERE}


Synthesis of 4-bromo-2,7-dioctyl-9-(octylamino)benzo[lmn][3,8]phenanthroline1,3,6,8(2H,7H)-tetraone (1)

To a solution of -octylamine (500 mg, $3.87 \mathrm{mmol})$, sodium $t$-butoxide (558 mg, $5.81 \mathrm{mmol})$ and palladium acetate $(112 \mathrm{mg}, 0.50 \mathrm{mmol})$ in toluene was added 4,9-dibromo-2,7dioctylbenzo[lmn][3,8]phenanthroline-1,3,6,8(2H,7H)-tetraone $(2.51 \mathrm{~g}, 3.87 \mathrm{mmol})$ followed by the addition of tri-t-butylphosphine (404 mg, $2 \mathrm{mmol}$ ) at room temperature. The resulting suspension was refluxed overnight. Thin-layer chromatography indicated the presence of a product, and the reaction mixture was filtered through Celite followed by solvent evaporation. The crude mass was subjected to column chromatography on silica gel (hexane/ethyl acetate 9.5: 0.5 ) to yield $870 \mathrm{mg}(32.3 \%)$ of 1 as a light pink solid. $\mathrm{M}$. Pt. = 110-111 ${ }^{\circ} \mathrm{C} ;{ }^{1} \mathrm{H}$ NMR $\left(\mathrm{CD}_{2} \mathrm{Cl}_{2}, 300 \mathrm{MHz}, \delta / \mathrm{ppm}\right): 10.09$ (t, 1H, NH), 8.86 (s, 1H, NDI), $8.28(\mathrm{~s}, 1 \mathrm{H}, \mathrm{NDI}), 4.24-4.17(\mathrm{t}, J=7.2 \mathrm{~Hz}, 4 \mathrm{H}), 3.71-3.62(\mathrm{~m}, 2 \mathrm{H}), 1.98-1.87(\mathrm{~m}, 2 \mathrm{H}), 1.82-$ $1.71(\mathrm{~m}, 4 \mathrm{H}), 1.49-1.21(\mathrm{~m}, 30), 0.98-0.87(\mathrm{~m}, 9 \mathrm{H}) ;{ }^{13} \mathrm{C} \mathrm{NMR}\left(\mathrm{CDCl}_{3}, 75 \mathrm{MHz}, \delta / \mathrm{ppm}\right)$ : $165.80,161.85,161.67,161.26,151.68,138.10,128.48,127.24,123.32,123.17,121.25$, $120.37,120.14,99.73,53.42,43.39,41.42,40.51,31.81,31.79,29.38,29.29,29.22,29.16$, 27.99, 27.95, 27.16, 27.03, 22.64, 12.09; HRMS (MALDI-TOF): calculated for $\mathrm{C}_{38} \mathrm{H}_{54} \mathrm{BrN}_{3} \mathrm{O}_{4}[\mathrm{~m} / \mathrm{z}]=696.3370$, found 696.3380 .

Synthesis of 9,9'-(5,5-dioctyl-5H-dibenzo[b,d]silole-3,7-diyl)bis(2,7-dioctyl-4(octylamino)benzo[lmn][3,8]phenanthroline-1,3,6,8(2H,7H)-tetraone) (B3)

5,5-Dioctyl-3,7-bis(4,4,5,5-tetramethyl-1,3,2-dioxaborolan-2-yl)-5H-dibenzo[b,d] silole (200 mg, $0.304 \mathrm{mmol}$ ) and compound 1 (635 mg, $0.91 \mathrm{mmol})$ were dissolved in 1,2dimethoxyethane $(30 \mathrm{~mL})$ in a $100 \mathrm{~mL}$ round bottom flask followed by the addition of cesium carbonate $(293 \mathrm{mg}, 0.903 \mathrm{mmol})$ at room temperature. The resulting suspension was stirred for $30 \mathrm{~min}$ and degassed by vacuum $/ \mathrm{N}_{2}$ purging (3 times) before 
tetrakis(triphenylphosphine)palladium(0) $\left[\mathrm{Pd}\left(\mathrm{PPh}_{3}\right)_{4}\right](58 \mathrm{mg}, 0.05 \mathrm{mmol})$ was added. The resulting dark yellow suspension was stirred at $120^{\circ} \mathrm{C}$ overnight. The solvent was evaporated off to get crude yellowish-red solid, which was subjected to flash chromatography $\left(\mathrm{SiO}_{2}, 1: 1\right.$ $-2: 1, \mathrm{CH}_{2} \mathrm{Cl}_{2} / \mathrm{n}$-hexane) to afford a red solid. This red solid was then crystallized from $n$ hexane to afford $\mathbf{B} 3$ as a shiny red powder $(310 \mathrm{mg}, 62.2 \%)$. M. Pt. $=201-202{ }^{\circ} \mathrm{C} ;{ }^{1} \mathrm{H} \mathrm{NMR}$ $\left(\mathrm{CD}_{2} \mathrm{Cl}_{2}, 300 \mathrm{MHz}, \delta / \mathrm{ppm}\right): 10.13(\mathrm{t}, 2 \mathrm{H}, \mathrm{NH}), 8.61$ (s, 2H, NDI), 8.35 (s, 2H, NDI),8.05$7.98(\mathrm{~d}, J=7.1 \mathrm{~Hz}, 2 \mathrm{H}), 7.76(\mathrm{~s}, 2 \mathrm{H}), 7.59-7.51(\mathrm{~d}, J=6.8 \mathrm{~Hz}, 2 \mathrm{H}), 4.25-4.21(\mathrm{t}, J=7.4 \mathrm{~Hz}$, 4H), 4.16-4.03 (t, $J=7.4 \mathrm{~Hz}, 4 \mathrm{H}), 3.71-3.62(\mathrm{~m}, 4 \mathrm{H}), 1.98-1.87(\mathrm{~m}, 4 \mathrm{H}), 1.82-1.67(\mathrm{~m}, 8 \mathrm{H})$, $1.49-1.19(\mathrm{~m}, 84 \mathrm{H}), 1.11-1.06(\mathrm{~m}, 4 \mathrm{H}), 0.98-0.87(\mathrm{~m}, 12 \mathrm{H}), 0.83-0.79(\mathrm{t}, J=7.1 \mathrm{~Hz}, 12 \mathrm{H})$; ${ }^{13} \mathrm{C} \mathrm{NMR}\left(\mathrm{CDCl}_{3}, 75 \mathrm{MHz}, \delta / \mathrm{ppm}\right): 166.66,163.14,163.08,152.33,147.68,141.85,140.63$, $138.22,135.53,134.05,130.97,129.30,128.73,123.52,122.95,120.91,120.84,120.38$, $100.26,43.70,40.58,33.93,32.27,32.23,32.20,29.88,29.77,29.67,29.59,29.56,28.42$, 27.56, 27.41, 24.44, 23.04, 14.21, 12.78; HRMS (MALDI-TOF): calculated for $\mathrm{C}_{104} \mathrm{H}_{148} \mathrm{~N}_{6} \mathrm{O} 8 \mathrm{Si}[\mathrm{M}+\mathrm{Na}]^{+}=1661.1057 \mathrm{~m} / z$, found 1661.1051.

\section{Results and discussion}

\subsection{Synthesis and characterization}

Compound B3 was synthesized as per reaction scheme 1 [For ${ }^{1} \mathrm{H}$ NMR and ${ }^{13} \mathrm{C}$ NMR spectra, please see supplementary information (SI)]. As expected, B3 exhibited excellent solubility in a variety of common organic solvents, such as chloroform, dichlorobenzene and toluene (for instance, $>30 \mathrm{mg} / \mathrm{mL}$ in $o$-dichlorobenzene), owing to the presence of the eight -octyl lipophilic chains. High solubility of organic semiconducting materials is one of the prime requirements for the fabrication of large area roll-to-roll solution-processable organic electronic devices, such as organic solar cells, and B3 fulfils this criterion. TGA revealed that B3 exhibits excellent thermal stability and is stable up to $350{ }^{\circ} \mathrm{C}$, a finding that strongly supports the high temperature annealing of P3HT:B3 devices and is consistent with DSC plot 
of B3 (see Fig. S1, SI).

\subsection{Optical and electrochemical properties}

The UV-Vis spectral absorptivity of B3 was measured in chloroform solution and is represented in Fig. 2. In solution, an absorption maximum $\left(\lambda_{\max }\right)$ at $536 \mathrm{~nm}\left(\varepsilon=47,030 \mathrm{M}^{-1}\right.$ $\mathrm{cm}^{-1}$; solution concentration $=3.05 \mu \mathrm{m}$ ) with an onset at $600 \mathrm{~nm}$ was measured for $\mathbf{B} 3$, and $\lambda_{\max }$ at $552 \mathrm{~nm}$ with an onset at $630 \mathrm{~nm}$ was measured in the thin solid film.

\section{FIGURE 2 GOES HERE}

The thin film absorption spectrum showed a bathochromic shift of about $16 \mathrm{~nm}$ when compared with the solution spectrum of B3, a finding that is consistent with our previous work $[32,35]$. The red shift in solid state is attributed to inter-/intramolecular interaction arising from the free hydrogen atoms. The blend film of P3HT:B3 (1:1 w/w) exhibited quenching of the photoluminescence [see Fig. S2, SI], a finding that is consistent with literature reporting non-fullerene electron acceptors [30]. The electrochemical property of B3 was also investigated using cyclic voltammetry. Cyclic voltammetry (CV) was carried out in freshly distilled dichloromethane at a scan rate of $50 \mathrm{mV} \mathrm{sec}$. As shown in Fig. 3, B3 exhibited two reversible reduction waves, a result that is consistent with literature reported materials [30], and suggests the suitability of $\mathbf{B} 3$ as an electron acceptor.

\section{FIGURE 3 GOES HERE}

The HOMO energy of B3 was estimated on a spin coated thin film using PESA and the LUMO energy was calculated by adding the bandgap to the HOMO value (see Fig. S3 and Table $\mathrm{S} 1$ in $\mathrm{SI})$. The HOMO of $\mathbf{B} 3$ is very low $(-5.92 \mathrm{eV})$ which is primarily due to the 
presence of two strong electron withdrawing NDI groups at the ends of central DBS functionality. The LUMO of $\mathbf{B} 3$ is matching very well with that of $\mathrm{PC}_{61} \mathrm{BM}$, which clearly indicates the significance of maintaining control of the LUMO energy of non-fullerene acceptors by a rational design approach. This lowering of HOMO energy levels is also very important to make materials more stable at ambient conditions. To compare experimental energy levels with respect to the electron density distribution of molecular orbitals, we conducted density functional theory (DFT) calculations using the Gaussian 09 suite of programmes and the B3LYP/6-311+G(d,p)//B3LYP/6-31G(d) level of theory [36]. We observed that the HOMO density of B3 was homogeneously populated over the whole molecular backbone, with major and sizable contribution from the central DBS block and the peripheral nitrogen atoms respectively. The participation of terminal nitrogen atoms clearly corroborates the design principle of $\mathbf{B} 3$ that the functionalities carrying such atoms can indeed play a significant role in tuning energy levels, and to enhance the solubility profile of the material at the same time. The LUMO was primarily distributed over the NDI functionalities. Such a HOMO-LUMO density distribution is vital for an optimum band gap. The DFT distribution is shown in Fig. 4, and Fig 5 depicts the energy level diagram.

\section{FIGURE 4 GOES HERE}

\section{FIGURE 5 GOES HERE}

\subsection{Photovoltaic properties}

After establishing that $\mathbf{B} 3$ possesses promising optical properties and energy levels that are similar to $\mathrm{PC}_{61} \mathrm{BM}$, we fabricated solution-processable $\mathrm{BHJ}$ devices. The classical donor polymer P3HT was used as a $p$-type semiconducting component along with B3 (n-type) to generate a blend solution and to cast an active layer on top of the PEDOT:PSS surface. The 
BHJ device architecture used was ITO/PEDOT:PSS (38 nm)/active layer/Ca (20 nm)/Al (100 nm) where the active layer was a 1:1 blend of $\mathrm{P} 3 \mathrm{HT} / \mathbf{B} 3$, spin-casted from $o$-dichlorobenzene.

\section{FIGURE 6 GOES HERE}

These primitive BHJ devices yielded reasonable performance and the photovoltaic cell parameters, $V_{\mathrm{oc}}$, short circuit current density $\left(J_{\mathrm{sc}}\right), \mathrm{FF}$ and PCE, reached $0.64 \mathrm{~V}, 3.40$ $\mathrm{mA} / \mathrm{cm}^{2}, 53.4 \%$ and $1.16 \%$, respectively. Notably, all the devices yielded very high FF values. In fact, the value of $\mathrm{FF} \sim 53 \%$ is among the highest values reported for a single junction BHJ device based on a novel non-fullerene electron acceptor. The respective $J-V$ curve is shown in Fig. 6. The analysis of the incident-photon-to-current conversion efficiency (IPCE) measurement of the BHJ device indicated a broad spectrum IPCE over the visible range which levels out at a value of $26 \%$ at around $550 \mathrm{~nm}$ (see Fig. 7).

\section{FIGURE 7 GOES HERE}

Even though the IPCE value is moderate, the result itself is significant with a view of using B3 in combination with low band gap conjugated donors, polymers or small molecules so that the charge generation could be achieved over a broad range of wavelengths. The physical microstructure of the blend surface was examined using atomic force microscopy (AFM) in tapping mode. The actual surface morphology in terms of phase and height images of as-cast B3 $(\mathrm{a}, \mathrm{b})$ and the P3HT:B3 $(1: 1, \mathrm{w} / \mathrm{w})$ blend annealed at $110^{\circ} \mathrm{C}$ for $5 \mathrm{~min}(\mathrm{c}, \mathrm{d})$ is shown in

Fig. 8. Pristine B3 appears to have terrace-like morphology with large layered distinguishable platelets. On the other hand, the P3HT:B3 blended film exhibits smooth morphology and better intermixing of donor and acceptor components, with crystalline grains and smaller size 
domains with a root-mean square (RMS) roughness of $2.3 \mathrm{~nm}$. This crystalline behaviour of blend film indicates self-organization of P3HT that can be beneficial for charge transport in thin films [37].

\section{FIGURE 8 GOES HERE}

\subsection{Charge transport studies}

In order to determine the electron mobility of B3, we used both organic field effect transistor (OFET) and TOF techniques. In OFET devices, B3 was spin coated on the octyltrichlorosilane (OTS-C8) and octadecyl trichlorosilane (OTS-C18) self-assembled monolayer $(\mathrm{SAM})$ treated $\mathrm{Si} / \mathrm{SiO}_{2}$ substrates. The highest electron mobility measured was 1.6 $\times 10^{-4} \mathrm{~cm}^{2} /$ Vs for the OTS-C18 treated substrate at room temperature (see Table S2 in SI). As the main intention of designing B3 was to use it as an electron acceptor in the organic solar cell devices, we also measured the electron mobility in vertical diode structure (resemblance to the solar cell device structure) by the time of flight photoconductivity (TOF-PC) method [38-39]. The detailed information about the TOF-PC technique was reported in an earlier publication [40]. ITO/B3 $(1200 \mathrm{~nm}) / \mathrm{Al}$; a simple diode structure was used and the electron mobility was measured directly by exciting a pulsed laser of wavelength $530 \mathrm{~nm}$ (pulse width $<5 \mathrm{~ns}, 1 \mathrm{HZ}$ repetition rate) on the thin film. In order to measure the electron mobility, a negative voltage bias was applied across the device. By varying the bias voltage using an oscilloscope, the TOF transients (raised due to electrons) are measured. The film thickness of B3 was around $1200 \mathrm{~nm}$ and the TOF measurements were carried out using integrated mode. The charge carrier mobility ( $\mu$ ) was measured using the relation of $\mu=d^{2} / t_{m} V$, where $d$ is the film thickness, $\mathrm{V}$ is applied voltage and $\mathrm{t}_{\mathrm{m}}$ is time taken to collect the maximum charge 
estimated from the transient. The calculated electron mobility for different electric fields using $t_{\mathrm{m}}$ obtained at various transients is shown in Fig. 9.

\section{FIGURE 9 GOES HERE}

The TOF-PC transients measured are shown in the inset of Fig. 9. The electron mobility for B3 acceptor was in the range of $2 \times 10^{-5} \mathrm{~cm}^{2} / \mathrm{Vs}$ at an applied electric field of $3.7 \times 10^{5} \mathrm{~V} / \mathrm{cm}$. The main benefits of the TOF-PC method are related with the measurement of charge mobility in dispersive samples and the contact effect doesn't hamper the measurement.

Although the material reported in this study was found to be highly suitable for the solutionprocessable $\mathrm{BHJ}$ devices and achieved promising PCE with a high FF, there still remains an appreciable scope to explore device strategies to enhance PCE. The performance can be improved by either using an effective interlayer, such as a metal oxide interlayer, which can facilitate the efficient charge extraction, or by devising processing methods, such as using solvent additives and solvent annealing techniques. Also, strategies such as the use of other conjugated polymers as well as small molecular donors can be applied to explore the use of B3 as a versatile non-fullerene acceptor. Working towards some of these strategies is the subject of current work in our laboratories. The discovery of materials, such as B3, possessing promising optoelectronic properties opens up the way to develop such motifs (based on the terminal NDI functionalities using peripheral donor atoms) and paves the way for such materials to be used for other organic electronic applications.

\section{Conclusions}


In summary, a novel, solution-processable small molecule B3 was designed and developed as a non-fullerene electron acceptor for organic BHJ devices. B3 exhibited excellent solubility, thermal stability, broad and strong absorption, appropriate energy levels matching with those of P3HT and good electron mobility. The P3HT:B3 blend film exhibited good nanoscale interpenetrating networks with structure, which is beneficial to charge separation and enhanced efficiency of the BHJ devices. Simple solution-processable BHJ devices based on the blend of P3HT and B3 exhibited PCEs as high as 1.16\% with a very high FF of $53.4 \%$, which, in fact, is among the highest FF values reported for solution-processable singlejunction BHJ devices based on small molecular non-fullerene acceptors. The work illustrated herein indicates that $\mathbf{B} 3$ indeed is a promising non-fullerene electron acceptor that has the potential to be added to the molecular library of $n$-type materials. The optimization of this work as well as work on a few of the strategies mentioned above is the subject of on-going research in our laboratories.

\section{Acknowledgements}

S.V.B acknowledges financial support from the Australian Research Council (ARC), Australia under a Future Fellowship Scheme (FT110100152). The CSIRO Materials Science and Engineering (CMSE) Clayton, Victoria is acknowledged for providing support through a visiting fellow position (A.G.). We also acknowledge Hemlata Patil for TGA and DSC measurements. P.S. is thankful to the ARC Future Fellowship Scheme (FT130101337) at Queensland University of Technology (QUT), Brisbane QLD.

\section{References}

[1] Lin Y, Li Y, Zhan X. Small molecule semiconductors for high-efficiency organic photovoltaics. Chem Soc Rev 2012;41:4245-72. 
[2] Li Y. Molecular design of photovoltaic materials for polymer solar cells: toward suitable electronic energy levels and broad absorption. Acc Chem Res 2012;45:723-33.

[3] Roncali J. Molecular bulk heterojunctions: an emerging approach to organic solar cells. Acc Chem Res 2009;42:1719-30.

[4] Cheng YJ, Yang SH, Hsu CS. Synthesis of conjugated polymers for organic solar cell applications. Chem Rev 2009;109:5868-923.

[5] Hains A, Liang Z, Woodhouse M, Gregg B. Molecular semiconductors in organic photovoltaic cells. Chem Rev 2010;110:6689-735.

[6] You JB, Dou LT, Yoshimura K, Kato T, Ohya K, Moriarty T, Emery K, Chen CC, Gao J, Li G, Yang Y. A polymer tandem solar cell with $10.6 \%$ power conversion efficiency. Nat Commun 2013;4:1446-55.

[7] Brunetti FG, Gong X, Tong M, Heeger AJ, Wudl F. Strain and hückel aromaticity: driving forces for a promising new generation of electron acceptors in organic electronics. Angew Chem Int Ed 2010;49:532-6.

[8] Brunetti FG, Kumar R, Wudl F. Organic electronics from perylene to organic photovoltaics: painting a brief history with a broad brush. J Mater Chem 2010;20:2934-48. [9] Shin RYC, Sonar P, Siew PS, Chen ZK, Sellinger A. Electron-accepting conjugated materials based on 2-vinyl-4,5-dicyanoimidazoles for application in organic electronics. J. Org Chem 2009;74:3293-98.

[10] Sonar P, Lim JPF, Chan KL. Organic non-fullerene acceptors for organic photovoltaics. Energy Environ Sci 2011;4:1558-74.

[11] Lin Y, Zhan X. Non-fullerene acceptors for organic photovoltaics: an emerging horizon. Mater Horiz 2014;1:470-88.

[12] Anthony JE. Small-molecule, nonfullerene acceptors for polymer bulk heterojunction organic photovoltaics. Chem Mater 2011;23:583-90. 
[13] Sonar P, Ng GM, Lin TT, Dodabalapur A, Chen ZK. Solution processable low bandgap diketopyrrolopyrrole (DPP) based derivatives: novel acceptors for organic solar cells. J Mater Chem 2010;20:3626-36.

[14] Li Y, Sonar P, Murphy L, Hong W. High mobility diketopyrrolopyrrole (DPP)-based organic semiconductor materials for organic thin film transistors and photovoltaics. Energy Environ Sci 2013;6:1684-1710.

[15] Nielsen CB, Turbiez M, McCulloch I. Recent advances in the development of semiconducting DPP-containing polymers for transistor applications. Adv Mater $2013 ; 25: 1859-80$.

[16] Yuen JD, Wudl F. Strong acceptors in donor-acceptor polymers for high performance thin film transistors. Energy Environ Sci 2013;6:392-406.

[17] Karsten BP, Bijleveld JC, Janssen RAJ. Diketopyrrolopyrroles as acceptor materials in organic photovoltaics. Macromol Rapid Commun 2010;31:1554-59.

[18] Lin Y, Cheng P, Li Y, Zhan X. A 3D star-shaped non-fullerene acceptor for solutionprocessed organic solar cells with a high open-circuit voltage of $1.18 \mathrm{~V}$. Chem Commun 2012;48:4773-75.

[19] Eftaiha AF, Sun JP, Hill IG, Welch GC. Recent advances of non-fullerene, small molecular acceptors for solution processed bulk heterojunction solar cells. J Mater Chem A 2014;2:1201-13.

[20] Lin Y, Wang Y, Wang J, Hou J, Li Y, Zhu D, Zhan X. A star-shaped perylene diimide electron acceptor for high-performance organic solar cells. Adv Mater 2014;26:5137-42. [21] Lin Y, Wang J, Dai S, Li Y, Zhu D, Zhan X. A twisted dimeric perylene diimide electron acceptor for efficient organic solar cells. Adv Energy Mater 2014;4:1400420-25.

[22] Bloking JT, Han X, Higgs AT, Kastrop JP, Pandey L, Norton JE, Risko C, Chen CE, 
Brédas JL, McGehee MD, Sellinger A. Solution-processed organic solar cells with power conversion efficiencies of $2.5 \%$ using benzothiadiazole/imide-based acceptors. Chem Mater 2011;23:5484-90.

[23] Lin Y, Li Y, Zhan X. A solution-processable electron acceptor based on dibenzosilole and diketopyrrolopyrrole for organic solar cells. Adv Energy Mater 2013;3:724-28.

[24] Patil H, Zu WX, Gupta A, Chellappan V, Bilic A, et al. A non-fullerene electron acceptor based on fluorene and diketopyrrolopyrrole building blocks for solution-processable organic solar cells with an impressive open-circuit voltage. Phy Chem Chem Phy 2014; 16:23837-42.

[25] Woo CH, Holcombe TW, Unruh DA, Sellinger A, Fréchet JMJ. Phenyl vs alkyl polythiophene: a solar cell comparison using a vinazene derivative as acceptor. Chem Mater 2010;22:1673-79.

[26] Zhou Y, Ding L, Shi K, Dai YZ, Ai N, Wang J, Pei J. A non-fullerene small molecule as efficient electron acceptor in organic bulk heterojunction solar cells. Adv Mater 2012;24:957-961.

[27] Zhou T, Jia T, Kang B, Li F, Fahlman M, Wang Y. Nitrile-substituted QA derivatives: new acceptor materials for solution-processable organic bulk heterojunction solar cells. Adv Energy Mater 2011;1:431-439.

[28] Zhang X, Lu Z, Ye L, Zhan C, et al. A potential perylene diimide dimer-based acceptor material for highly efficient solution-processed non-fullerene organic solar cells with $4.03 \%$ efficiency. Adv Mater 2013;25:5791-97.

[29] Raynor AM, Gupta A, Patil H, Bilic A, Bhosale SV. A diketopyrrolopyrrole and benzothiadiazole based small molecule electron acceptor: design, synthesis, characterization and photovoltaic properties. RSC Adv 2014;4:57635-38. 
[30] Patil H, Gupta A, Bilic A, Bhosale SV, Bhosale SV. A solution-processable electron acceptor based on diketopyrrolopyrrole and naphthalenediimide motifs for organic solar cells. Tetrahedron Lett 2014;55:4430-32.

[31] Patil H, Gupta A, Bilic A, Jackson SL, Latham K, Bhosale SV. Donor-acceptor-donor modular small organic molecules based on the naphthalene diimide acceptor unit for solutionprocessable photovoltaic devices. J Electron Mater 2014;43:3243-54.

[32] Gupta A, Ali A, Bilic A, Gao M, Hegedus K, et al. Absorption enhancement of oligothiophene dyes through the use of a cyanopyridone acceptor group in solution-processed organic solar cells. Chem Comm 2012;48:1889-91.

[33] Gupta A, Armel V, Xiang W, Fanchini G, Watkins SE, MacFarlane DR, et al. The effect of direct amine substituted pushepull oligothiophene chromophores on dye-sensitized and bulk-heterojunction solar cells performance. Tetrahedron 2013;69:3584-92.

[34] Kumar RJ, Churches QI, Subbiah J, Gupta A, et al. Enhanced photovoltaic efficiency via light-triggered self-assembly. Chem Comm 2013;49:6552-54.

[35] Gupta A, Ali A, Singh TB, Bilic A, Bach U, Evans RA. Molecular engineering for panchromatic absorbing oligothiophene donor- $\pi$-acceptor organic semiconductors. Tetrahedron 2012;68:9440-47.

[36] Frisch MJ, Trucks GW, Schlegel HB, Scuseria GE, Robb MA, Cheeseman JR, et al. Gaussian 09, revision D.01. Wallingford CT: Gaussian Incorporation; 2013.

[37] Li G, Shrotriya V, Huang J, Yao Y, Moriarty T, Emery K, Yang Y. High-efficiency solution processable polymer photovoltaic cells by self-organization of polymer blends. Nat Mater 2005;4:864-8.

[38] Tan MJ, Goh WP, Jun L, Pundir G, Vijila C, Kuan CZ. Charge mobility and recombination in a new hole transporting polymer and its photovoltaic blend. ACS Appl Mater Interface 2010;2:1414-20. 
[39] Vijila C, Meng NG, Kuan CZ, Furong Z, Jin CS. Charge transport studies in electroluminescent biphenylyl substituted PPV derivatives using time-of-flight photoconductivity method. J Polym Sci B Polym Phys 2008;46:1159-66.

[40] Campbell AJ, Bradley DDC, Antoniadis H. Dispersive electron transport in an electroluminescent polyfluorene copolymer measured by the current integration time-of-flight method. Appl Phys Lett 2001;79:2133-35. 


\section{List of Figures}

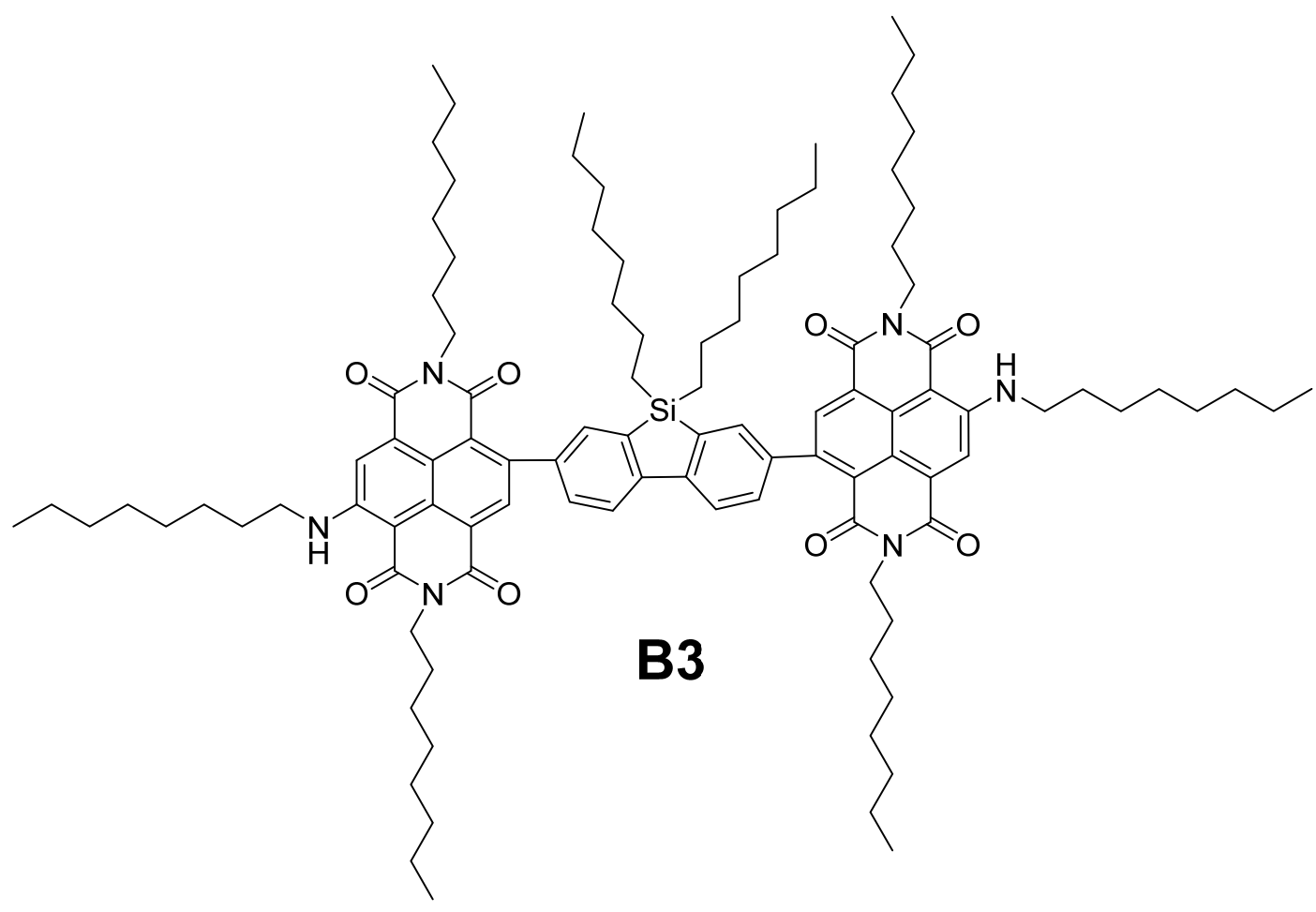

Fig. 1 Molecular structure of the newly designed and synthesized non-fullerene electron acceptor B3. 


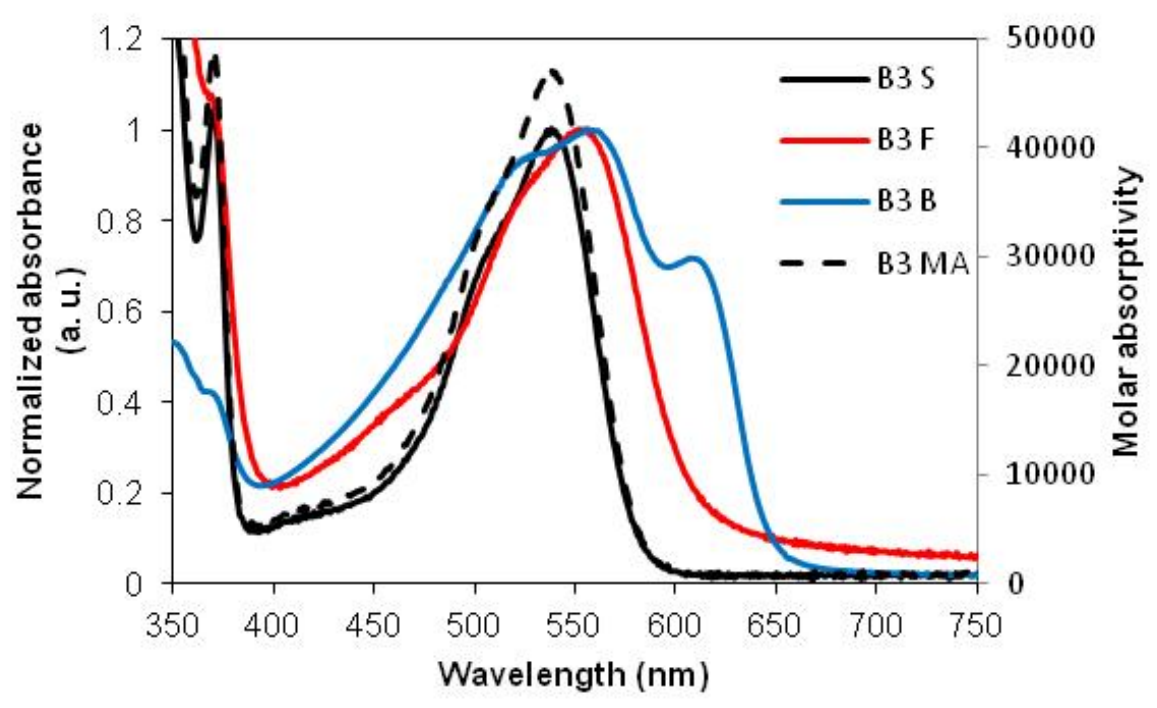

Fig. 2 UV-Vis absorption spectra of pristine film (B3 F; solid red line), 1:1 P3HT:B3 blend (B3 B; solid blue line), and in chloroform solution [B3 solution (S) and B3 molar absorptivity (MA)].

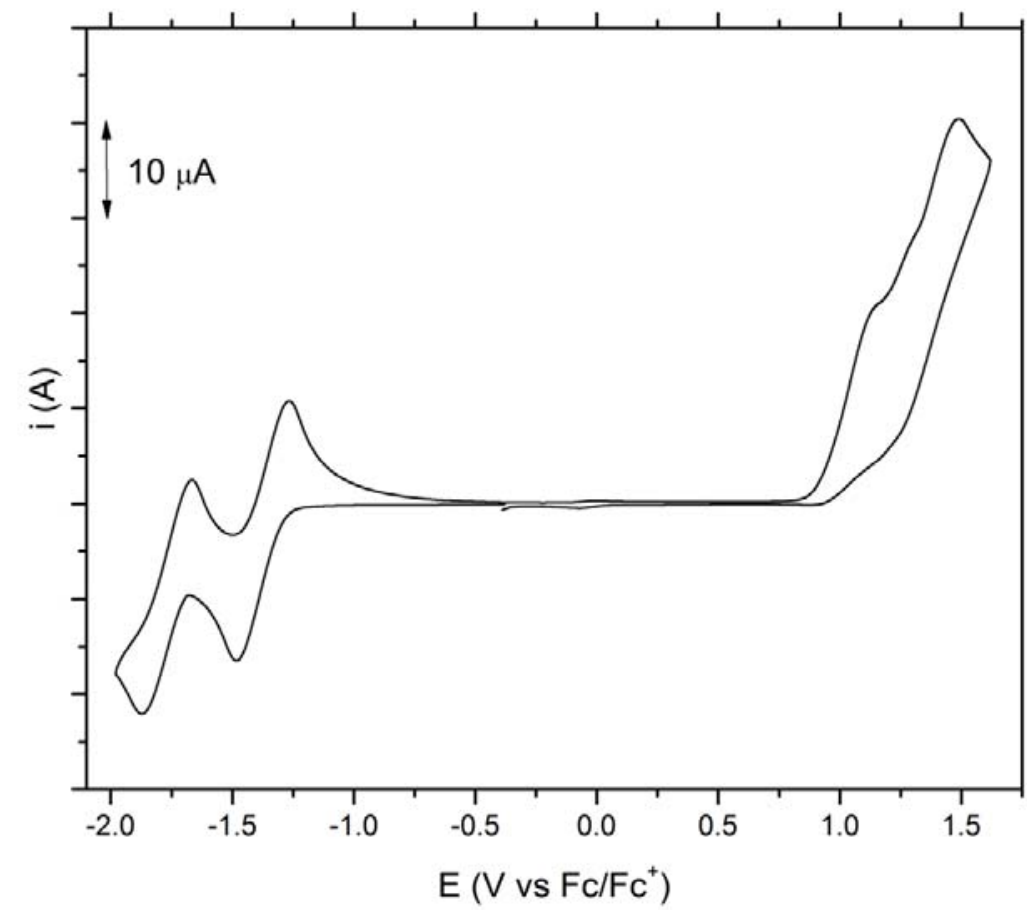

Fig. 3 Cyclic-voltammogram of B3, in freshly distilled dichloromethane at a sweep rate of 50 $\mathrm{mV} \mathrm{sec}-1$, showing two reversible reduction waves. 


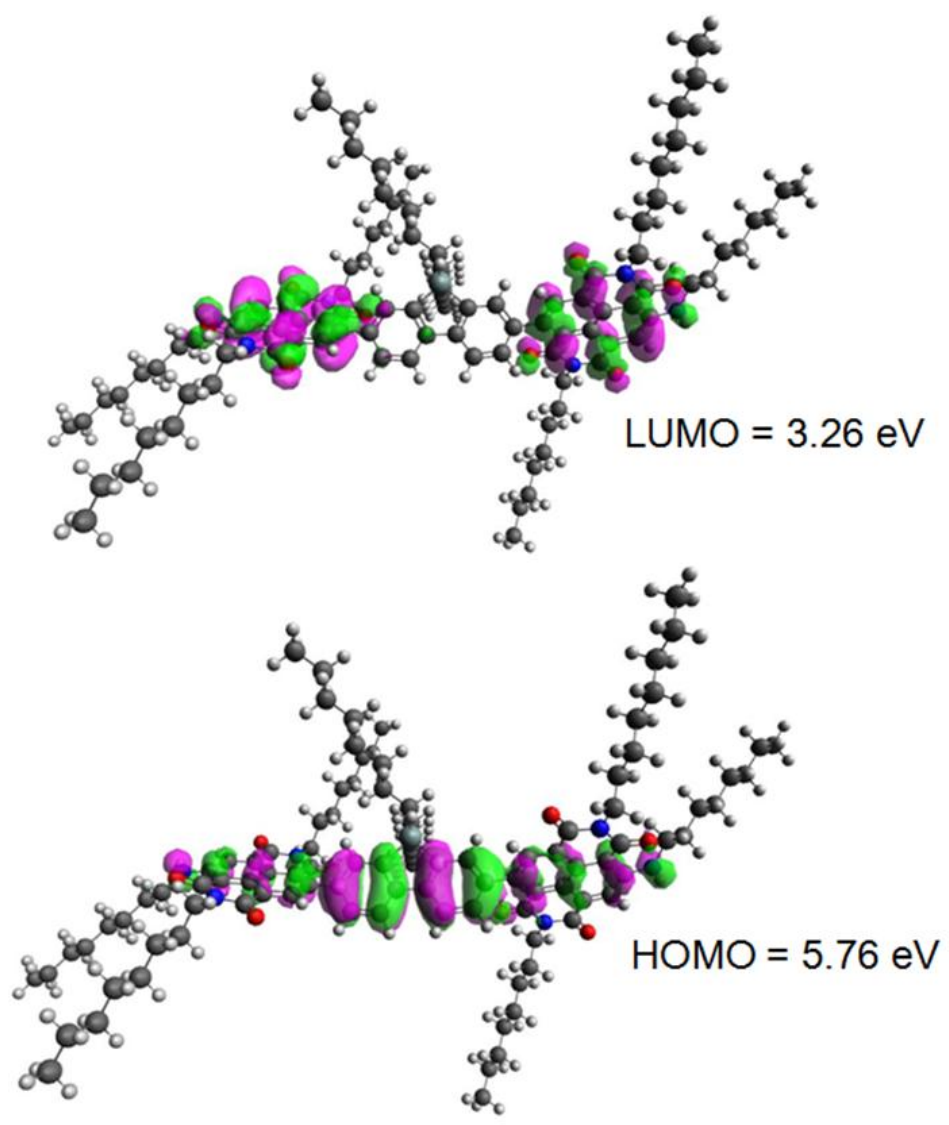

Fig. 4 Orbital density distribution for frontier molecular orbitals of B3. DFT calculations were performed using the Gaussian 09 suite of programs and B3LYP/6$311+\mathrm{G}(\mathrm{d}, \mathrm{p}) / / \mathrm{B} 3 \mathrm{LYP} / 6-31 \mathrm{G}(\mathrm{d})$ level of theory. 


\section{ITO/PEDOT:PSS/P3HT:B3/Ca/AI}

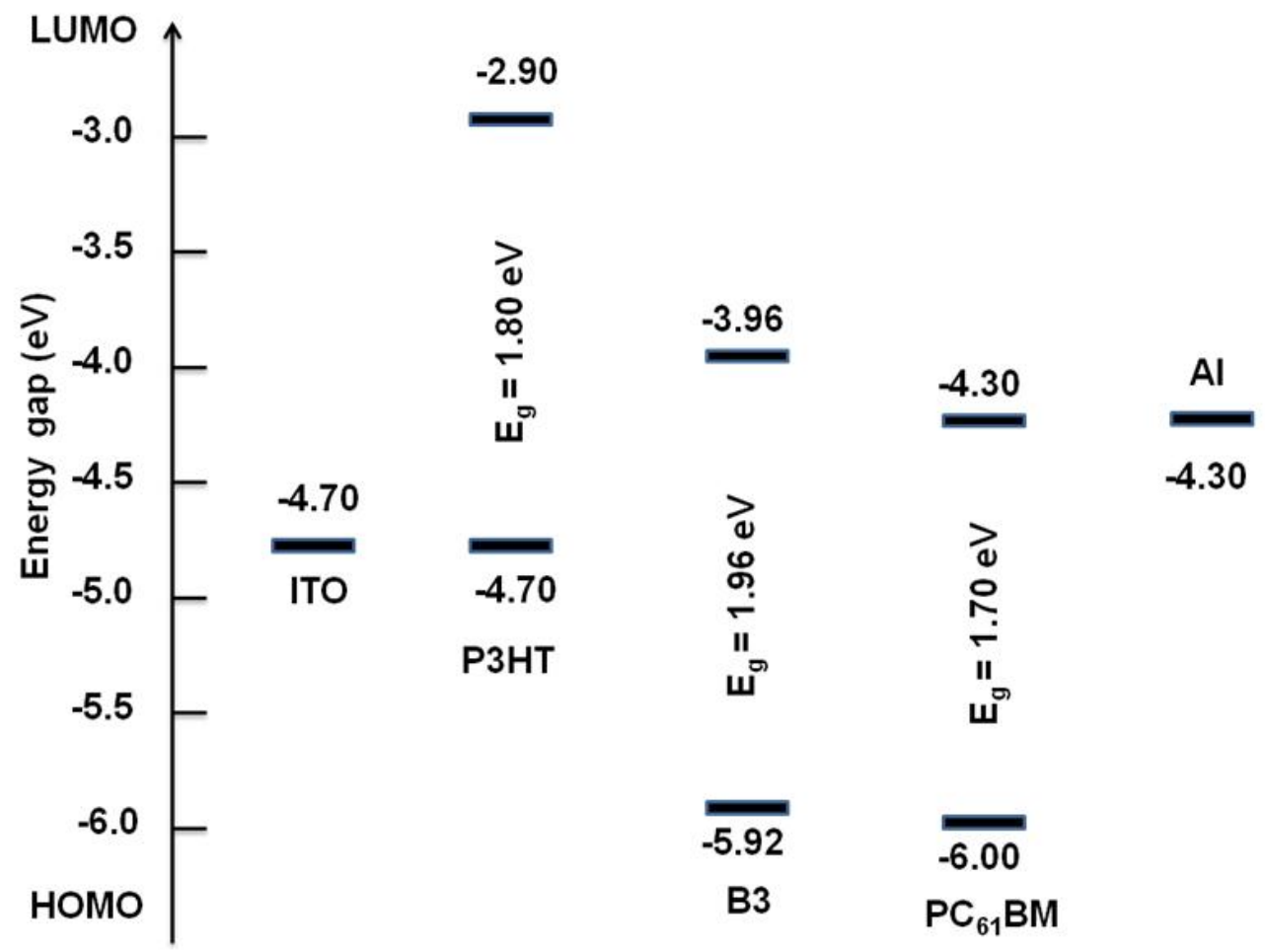

Fig. 5 Energy level diagram showing alignments of different components of the BHJ device architecture 


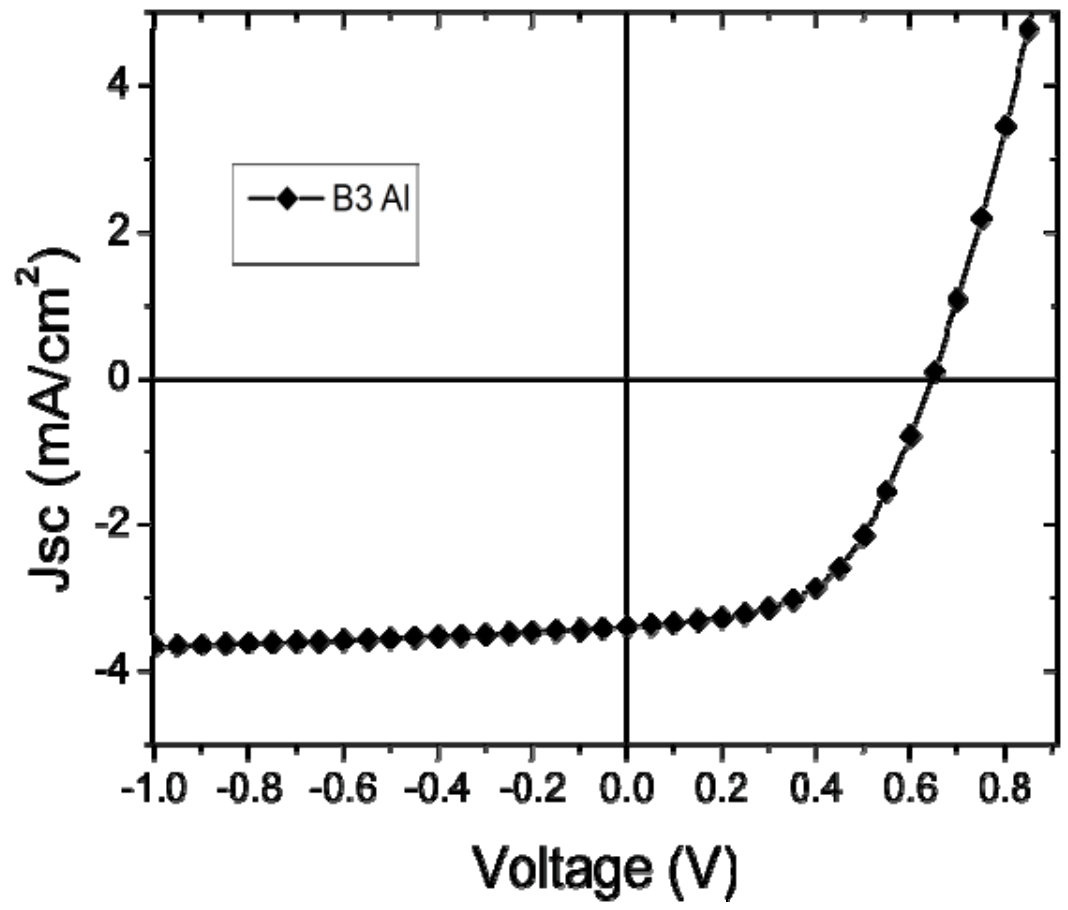

Fig. 6 Current density-voltage $(J-V)$ curve for the BHJ device based on B3 in blends with P3HT $(1: 1 \mathrm{w} / \mathrm{w})$ under simulated sunlight (AM 1.5, $\left.1000 \mathrm{~W} \mathrm{~m}^{-2}\right)$. Device structure is: ITO/PEDOT:PSS $(38 \mathrm{~nm}) /$ active layer/Ca $(20 \mathrm{~nm}) / \mathrm{Al}(100 \mathrm{~nm})$ where the active layer was a blend of B3 and P3HT spun on top of the PEDOT:PSS surface using $o$-dichlorobenzene. 


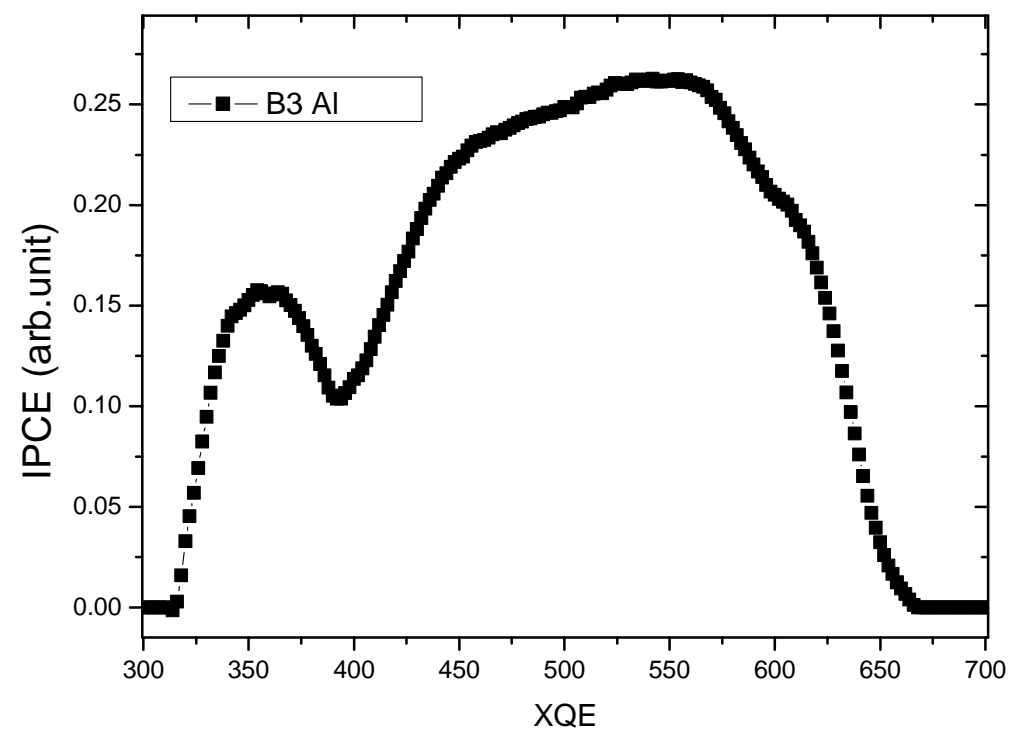

Fig. 7 IPCE spectrum measured for the P3HT:B3 based OPV device. 

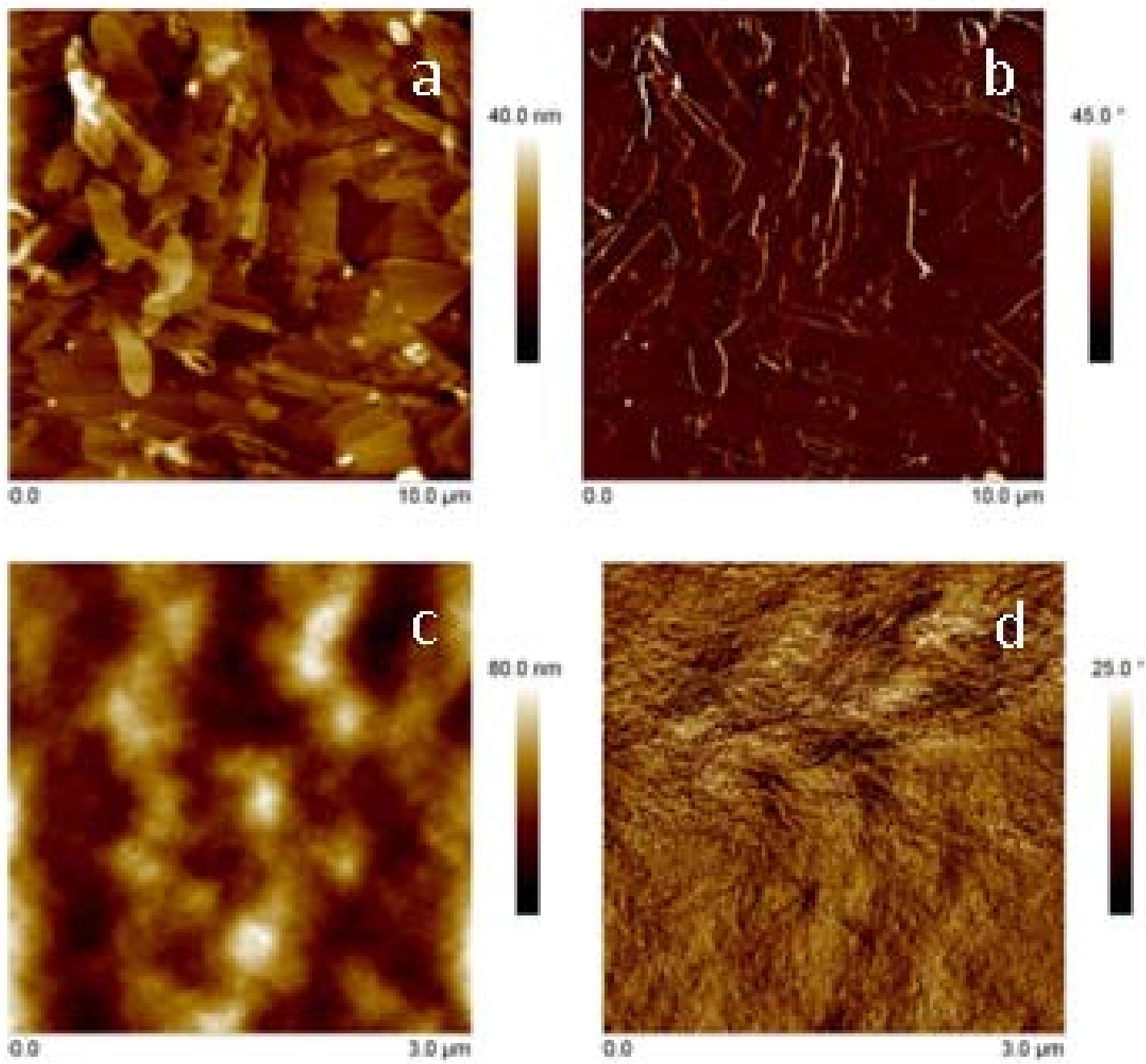

Fig. 8 AFM images for a thin film of as-casted B3 (a, b) and P3HT:B3 blend (c, d) annealed at $110{ }^{\circ} \mathrm{C}$ for $5 \mathrm{~min}(1: 1 \mathrm{blend}$ in $1 \mathrm{~mL} o$-dichlorobenzene, $1000 \mathrm{rpm} / \mathrm{s}$ for $1 \mathrm{~min})$. 


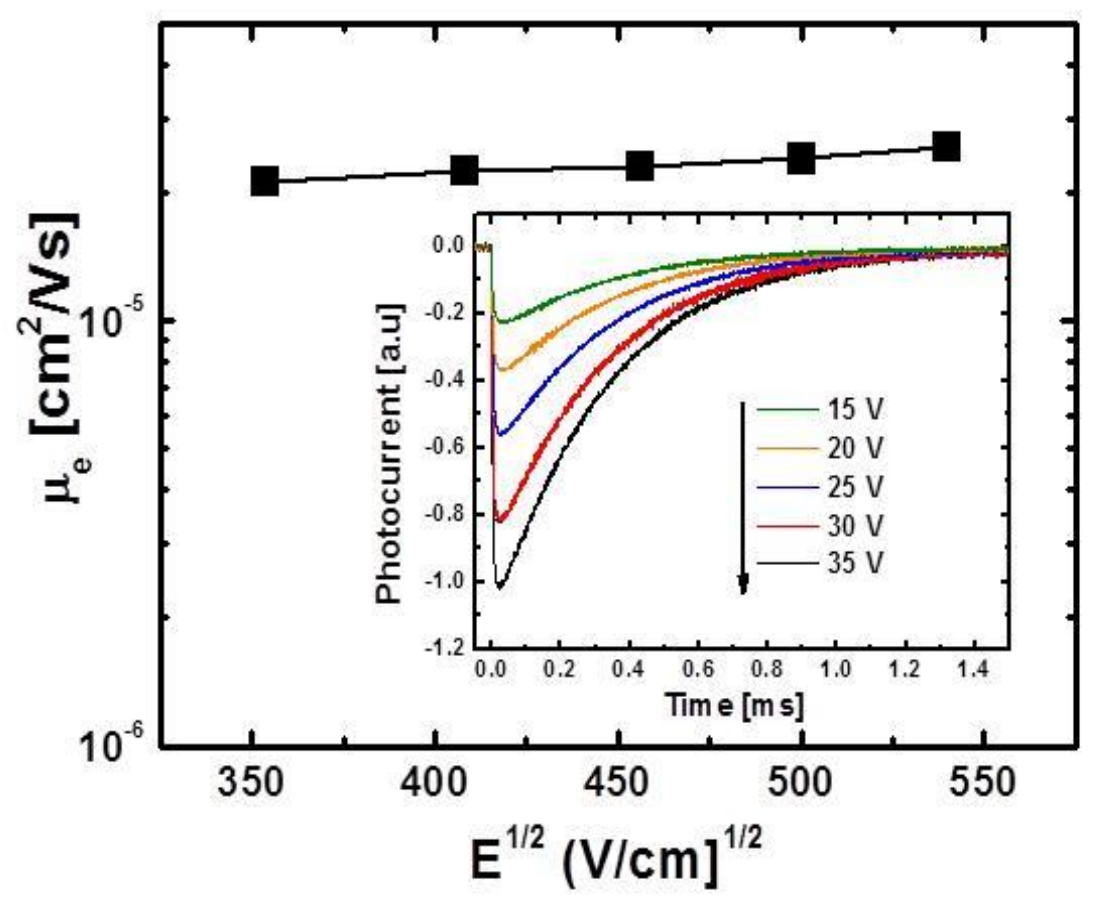

Fig. 9 Variation of electron mobility with applied electric field; Inset: current integrated TOF-PC transients for electrons measured for different applied voltages.

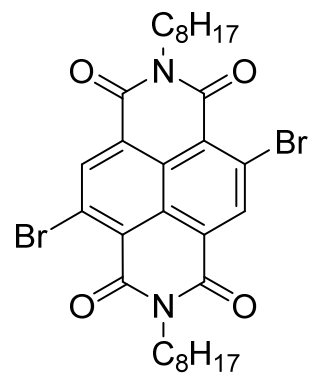

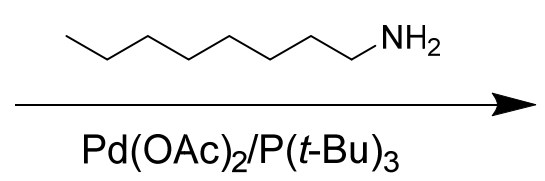
$t$-BuONa/toluene/reflux $32 \%$<smiles>CCCCN1C(=O)c2cc(NC(C)C)c3c4c(cc(Br)c(c24)C1=O)C(=O)N(CCCC)C3=O</smiles><smiles>CC[Si]1([13CH])CCCCc2ccc(B3OC(C)(C)c4ccc(B5OC(C)(C)C(C)(C)O5)cc43)cc21</smiles>

dimethoxyethane $/ 120^{\circ} \mathrm{C}$

$$
62 \%
$$

Scheme 1 Reaction strategy for the synthesis of B3. 


\section{Figure Captions}

Fig. 1 Molecular structure of the newly designed and synthesized non-fullerene electron acceptor B3

Fig. 2 UV-Vis absorption spectra of pristine film (B3 F; solid red line), 1:1 P3HT:B3 blend (B3 B; solid blue line), and in chloroform solution [B3 solution (S) and B3 molar absorptivity (MA)]

Fig. 3 Cyclic-voltammogram of B3, in freshly distilled dichloromethane at a sweep rate of 50 $\mathrm{mV} \mathrm{sec}{ }^{-1}$, showing two reversible reduction waves.

Fig. 4 Orbital density distribution for frontier molecular orbitals of B3. DFT calculations were performed using the Gaussian 09 suite of programs and B3LYP/6$311+\mathrm{G}(\mathrm{d}, \mathrm{p}) / / \mathrm{B} 3 \mathrm{LYP} / 6-31 \mathrm{G}(\mathrm{d})$ level of theory.

Fig. 5 Energy level diagram showing alignments of different components of the BHJ device architecture

Fig. 6 Current density-voltage $(J-V)$ curve for the BHJ device based on $\mathbf{B} 3$ in blends with P3HT (1: $1 \mathrm{w} / \mathrm{w})$ under simulated sunlight (AM 1.5, $\left.1000 \mathrm{~W} \mathrm{~m}^{-2}\right)$. Device structure is: ITO/PEDOT:PSS $(38 \mathrm{~nm}) /$ active layer/Ca $(20 \mathrm{~nm}) / \mathrm{Al}(100 \mathrm{~nm})$ where the active layer was a blend of B3 and P3HT spun on top of the PEDOT:PSS film using $o$-dichlorobenzene.

Fig. 7 IPCE spectrum measured for the P3HT:B3 based OPV device.

Fig. 8 AFM images for a thin film of as-casted B3 (a, b) and P3HT:B3 blend (c, d) annealed at $110{ }^{\circ} \mathrm{C}$ for $5 \mathrm{~min}(1: 1 \mathrm{blend}$ in $1 \mathrm{~mL} o$-dichlorobenzene, $1000 \mathrm{rpm} / \mathrm{s}$ for $1 \mathrm{~min})$.

Fig. 9 Variation of electron mobility with applied electric field; Inset: current integrated TOF-PC transients for electrons measured for different applied voltages.

Scheme 1 Reaction strategy for the synthesis of B3. 